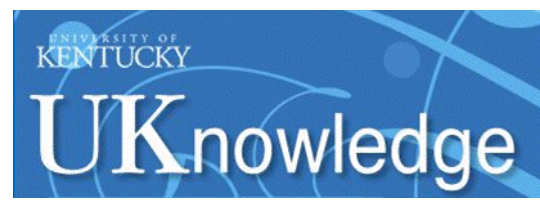

University of Kentucky

UKnowledge

$1-1-2017$

\title{
Childhood Drinking and Depressive Symptom Level Predict Harmful Personality Change
}

\author{
Elizabeth N. Riley \\ University of Kentucky, elizabeth.n.riley@uky.edu \\ Gregory T. Smith \\ University of Kentucky, gsmith@uky.edu
}

Follow this and additional works at: https://uknowledge.uky.edu/psychology_facpub

Part of the Child Psychology Commons, Clinical Psychology Commons, and the Substance Abuse and Addiction Commons

Right click to open a feedback form in a new tab to let us know how this document benefits you.

\section{Repository Citation}

Riley, Elizabeth N. and Smith, Gregory T., "Childhood Drinking and Depressive Symptom Level Predict Harmful Personality Change" (2017). Psychology Faculty Publications. 163.

https://uknowledge.uky.edu/psychology_facpub/163

This Article is brought to you for free and open access by the Psychology at UKnowledge. It has been accepted for inclusion in Psychology Faculty Publications by an authorized administrator of UKnowledge. For more information, please contact UKnowledge@lsv.uky.edu. 


\section{Childhood Drinking and Depressive Symptom Level Predict Harmful Personality Change}

Digital Object Identifier (DOI)

https://doi.org/10.1177/2167702616661716

Notes/Citation Information

Published in Clinical Psychological Science, v. 5, issue 1, p. 85-97.

Elizabeth N. Riley and Gregory T. Smith, Childhood Drinking and Depressive Symptom Level Predict Harmful Personality Change, Clinical Psychological Science 5(1) pp. 85-97. Copyright @ 2016 The Author(s). DOI: https://doi.org/10.1177/2167702616661716

The copyright holder has granted the permission for posting the article here.

The document available for download is the authors' post-peer-review final draft of the article. 


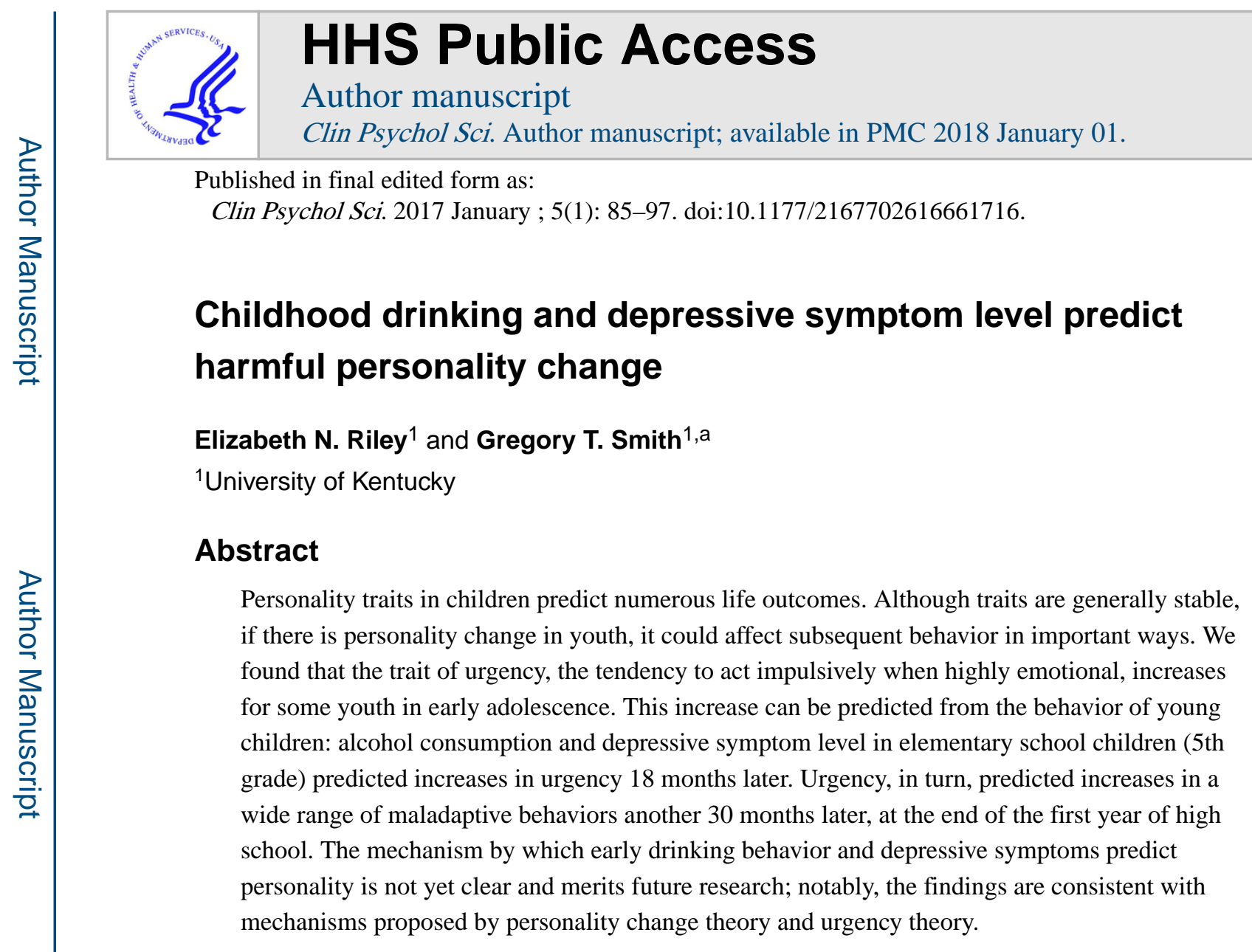

\section{Introduction}

One traditional and highly fruitful line of inquiry for understanding the onset of, and increases in, engagement in impulsive, maladaptive behaviors has been to identify personality traits that increase the risk of engagement in such behaviors (Settles, Cyders, \& Smith, 2010; Settles, Zapolski, \& Smith, 2014; Sher \& Trull, 1994; Smith \& Guller, 2014; Tarter, 1988). This paper reports on tests of hypotheses concerning the reverse relationship: we tested whether high-risk behavior by youth predicted subsequent increases in maladaptive personality. Although tests of whether behavior predicts maladaptive personality have rarely been conducted (but see Blonigen Durbin, Hicks, Johnson, McGue, \& Iacono, 2015; Horvath, Milich, Lynam, Leukefeld, \& Clayton, 2004; Littlefield, Verges, Wood, \& Sher, 2012), such tests are important. Because high-risk traits increase risk for harm transdiagnostically, i.e. in multiple forms of dysfunction (Smith \& Cyders, 2016; Zuckerman, 1994), behaviors that predict increased levels of high-risk traits may thus have transdiagnostic etiological importance.

\footnotetext{
${ }^{a}$ Corresponding author information: gsmith@email.uky.edu; Phone: (859) 257-6454; Fax: (859) 323-1979.

This research was conducted at: The University of Kentucky, Department of Psychology, 125 Kastle Hall, Lexington, KY 40506-0044 Permanent Address: College of Arts and Sciences, Department of Psychology, 125 Kastle Hall, Room 106, Lexington, KY 40506-0044

Elizabeth N. Riley developed the study concept. Both E. Riley and Gregory T. Smith contributed to the study design. Data collection took place over several years and was conducted by the two authors and others in the lab of G. Smith. Both authors conducted the data analysis and interpretation; G. Smith provided supervision of E. Riley in this process. E. Riley drafted the paper, and G. Smith provided critical revisions. All authors approved the final version of the paper for submission.
} 
The specific model we used to test this possibility was whether engagement in rare and dysfunctional behaviors during elementary school, such as alcohol consumption, smoking, and binge eating, as well as the early presence of depressive symptoms, predicted subsequent increases in the high-risk trait of urgency, which reflects the disposition to act rashly when highly emotional (Cyders \& Smith, 2008a). To introduce this test, we briefly review the role of personality in risk models, stability of personality and change within that stability, the role of urgency as a personality predictor of risk, and the problematic nature of very early engagement in drinking, smoking and binge eating.

\section{The Role of Personality in Risk Models}

With respect to risk for psychological dysfunction, personality is understood to operate as a distal and transdiagnostic risk factor; multiple studies document that personality predicts life trajectories as reflected in numerous outcomes, both positive and negative, in many domains of functioning (Roberts, Kuncel, Shiner, Caspi, \& Goldberg, 2007). Among the many outcomes predicted by personality are physical health, mortality, marital outcomes, interpersonal functioning, educational and occupational attainment, life happiness, engagement in substance abuse, and psychopathology (Costa \& McCrae, 1996; Roberts et al., 2007). The importance of personality in youth has become apparent for the prediction of both adult (Caspi, Harrington, Milne, Amell, Theodore, \& Moffitt, 2003; Shiner \& Masten, 2002) and adolescent (Smith, Guller, \& Zapolski, 2013) adjustment.

\section{Personality Stability and Change}

In addition to being highly heritable (Jang, Livesley, \& Vernon, 1996), individual differences in personality are remarkably stable across the lifespan (Costa, Herbst, McCrae \& Siegler, 2000; Costa \& McCrae, 1996). Across decades of adult life, stability coefficients (correlations corrected for unreliability) range from .60 to .80 (McCrae \& Costa, 1994; Roberts \& DelVecchio, 2000), with similar but slightly smaller coefficients representing stability from adolescence to adulthood.

In the context of this stability, there is growing appreciation for personality change, particularly during developmental transitions. A series of studies on the transition into adulthood has shown such change, which can occur in adaptive or maladaptive ways (Bleidorn, 2012; Blonigen et al., 2015; Roberts, Wood \& Caspi, 2008). Those who invest positively in their new adult roles, as reflected in job attainment, work satisfaction, and financial security tend to experience positive increases in conscientiousness and self-control (Roberts, Caspi \& Moffitt, 2003). Those who respond negatively to the challenges of emerging adulthood, reflected in behaviors such as fighting with co-workers, stealing from the workplace, or using substances at work, tend to experience increases in negative emotionality and decreases in self-control (Roberts, Walton, Bogg, \& Caspi, 2006). There is also evidence that those who begin engagement in non-normative or risky behaviors far earlier than their peers tend to experience personality changes in the negative direction (Blonigen et al., 2015).

Theory holds that the process of personality change is likely to operate in what is sometimes called a bottom-up fashion. During developmental transitions, one takes on new social and 
achievement roles. Those new roles require engagement in new behaviors. Engagement in new behaviors that are reinforced by the environment leads, over time, to basic personality shifts consistent with investment in the new behaviors (Roberts et al., 2008). For example, engagement in a new behavior such as paying bills on time may be rewarded by the environment (perhaps in the form of a higher credit score, which allows the individual to buy a car). Thus, a new social role (adulthood), and repeated engagement in behaviors that reflect investment in that role, may result in a new environmental reward structure in which, for example, more conscientious behaviors are consistently reinforced, leading to an incremental increase in the personality trait of conscientiousness.

\section{The Trait of Urgency}

Urgency can readily be understood in terms of comprehensive models of personality (Costa \& McCrae, 1996): it is characterized by high levels of neuroticism and low levels of agreeableness and conscientiousness (Cyders \& Smith, 2008a). The trait of urgency has two facets. Negative and positive urgency refer to the disposition to act rashly when in an unusually negative or positive mood, respectively (Cyders \& Smith, 2007, 2008a).

For several reasons, increases in the trait of urgency would be important clinically. First, multiple meta-analyses have identified urgency or its facets as particularly strong predictors of numerous addictive behaviors (Berg, Latzman, Bliwise \& Lilienfeld, 2015; Coskunpinar, Dir \& Cyders, 2013; Fischer, Smith \& Cyders, 2008; Stautz \& Cooper, 2013). Second, longitudinal studies have demonstrated that positive and/or negative urgency predict the subsequent onset of, or increases in, drinking frequency and quantity (Cyders, Flory, Rainer, \& Smith, 2009; Settles et al., 2010, 2014); tobacco smoking (Doran, Khoddam, Sanders, Schweizer, Trim, \& Myers, 2013), drug use (Zapolski, Cyders, \& Smith, 2009), risky sex (Zapolski et al., 2009), binge eating (Fischer, Peterson, \& McCarthy, 2013; Pearson, Combs, Zapolski, \& Smith, 2012), gambling (Cyders \& Smith, 2008b), non-suicidal self-injury (Riley, Combs, Jordan, \& Smith, 2015), and depression (Smith et al., 2013). Third, numerous prospective studies have documented this predictive role for urgency in children as young as late elementary school and middle school, thus suggesting that urgency's predictive role is not a downstream manifestation of scar effects from the consequences of ongoing psychopathology (Widiger \& Smith, 2008). Given urgency's predictive role, increases in this high-risk trait are likely associated with increases in transdiagnostic behavioral risk.

\section{Risky Behavior Engagement as a Predictor of Urgency Change}

The theoretical basis for hypothesizing that early engagement in risky, impulsive acts predicts urgency change is a combination of the bottom-up theory of personality change described above and the theory of urgency (Cyders \& Smith, 2008a; Smith \& Cyders, 2016). Consistent with personality change theory, early adolescent engagement in new behaviors that provide reinforcement may contribute to gradual changes in personality. More specifically, we felt that increases in urgency might best be predicted by engagement in behaviors that are (a) considered rash or impulsive in youth and (b) often engaged in when experiencing intense emotion. 
Early engagement in drinking, smoking, and binge eating behavior all represent plausible candidates to lead to increases in urgency. Engagement in these behaviors during early adolescence is rare (Combs, Pearson, \& Smith, 2011; Combs, Spillane, Caudill, Stark, \& Smith, 2012; Donovan, 2007) and is associated with both current and future harm (Chassin, Presson, Pitts, \& Sherman, 2000; Chung et al., 2012; Guttmannova et al., 2012; Kotler, Cohen Davies, Pine, \& Walsh, 2001; Stice \& Martinez, 2005). Nevertheless, each of the behaviors is thought also to provide immediate reinforcement (Doran et al., 2013; Pearson et al., 2012; Smyth et al., 2007; Swendson, Tennen, Carney, Affleck, Willard, \& Hromi, 2000). Each is often precipitated by intense emotion, whether subjective distress or unusually positive mood states, and functions to provide (a) relief from distress or (b) enhancement of a positive mood state (Baker, Brandon, \& Chassin, 2004; Doran et al., 2013; Haedt-Matt \& Keel, 2011; Settles et al., 2014; Smyth et al., 2007; Steinberg, Albert, Cauffman, Banich, Graham, \& Woolard, 2008; Swendson et al., 2000).

Each of the behaviors is described as rash or impulsive, because engagement in them often meets an immediate affective need but also undermines an individual's health, interests, or long-term goals (Birkley \& Smith, 2011; Cyders \& Smith, 2008a). Because of the potency of immediate reinforcement, these behaviors are reinforced incrementally over time, as is the disposition to engage in such behaviors. Urgency is one such disposition, and therefore, we hypothesized, it is reinforced and may thus increase over time.

Among these three behaviors, we were particularly interested in whether very early drinking predicts increases in urgency for two reasons. First, drinking may be a better predictor because in children as young as $5^{\text {th }}$ grade (wave 1 in the current study), more youth have consumed a drink of alcohol than have smoked a cigarette, and the meaning of binge eating in children so young is not yet entirely clear (Combs, Pearson, Zapolski, \& Smith, 2013; Tanofsky-Kraff et al., 2011). Second, simple drinker status in youth is highly predictive of alcohol use disorder symptoms (Chung et al., 2012), and the American Academy of Pediatricians (AAP) recommends screening for drinker status in youth (AAP \& National Institute on Alcohol Abuse and Alcoholism, NIAAA, 2011). As a result, drinker status in youth is being assessed more frequently. We thus sought to determine whether this assessment also facilitates prediction of personality change.

We also considered the possibility that early depressive symptomatology might predict subsequent increases in urgency. It may be that depressive symptoms, in part, reflect more frequent experiences of both stress and distress. Perhaps experiencing these emotions at a greater frequency increases the probability that, over time, one will be disposed to act in rash, impulsive ways to alleviate distress, resulting in increases in urgency.

\section{The Current Study}

We studied 1,906 youth in the spring of $5^{\text {th }}$ grade (the last year of elementary school), the fall of $7^{\text {th }}$ grade (18 months later, during middle school), and the spring of $9^{\text {th }}$ grade (30 months after the second assessment, the first year of high school). We first tested whether engagement in rash, maladaptive behaviors (drinking, smoking, and binge eating) and depressive symptom level, during elementary school, predicted increases in urgency 18 months later. Second, to evaluate whether middle school urgency does increase risk 
transdiagnostically, we tested whether middle school urgency predicted increases in drinking, smoking, binge eating, and depression by the end of the first year of high school. Support for these hypotheses would suggest that very early engagement in risky, maladaptive behaviors, as well as the experience of depression at a young age, is a marker of risk for multiple forms of future dysfunction, apparently due to maladaptive personality change.

Our hypotheses were specific to increases in the trait of urgency. To test for this specificity empirically, we conducted the same series of tests using three other personality dispositions thought to be related to impulsive action: sensation seeking, lack of planning (the disposition to act without forethought), and lack of perseverance (difficulty maintaining focus on a task in the face of distractions (Whiteside \& Lynam, 2001).

\section{Method}

Sample

Participants were 1906 youth in $5^{\text {th }}$ grade at the start of the study; they were drawn from urban, rural, and suburban backgrounds and represented 23 public schools in two school systems. The sample was equally divided between girls (49.9\%) and boys. At wave 1, most participants were 11 years old (66.8\%), $22.8 \%$ were 10 years old; $10 \%$ were 12 years old; and $.2 \%$ were either 9 or 13 years old. The ethnic breakdown of the sample was as follows: 60.9\%, European American, 18.7\% African American, 8.2 \% Hispanic, 3\% Asian American, and $8.8 \%$ other racial/ethnic groups.

\section{Measures}

Demographic and background questionnaire-Participants were asked to circle their gender, write in their current age (in years), and indicate which label(s) best described their ethnic background.

UPPS-P-Child Version, Urgency (Zapolski, Stairs, Settles, Combs \& Smith, 2010). Urgency is the label for a trait domain that includes two facets: positive and negative urgency represent the dispositions to act rashly when experiencing intense positive or negative mood, respectively (Cyders \& Smith, 2007; Cyders \& Smith, 2008a). The two urgency scales consist of 8 items each and responses are on a four-point Likert scale from 1 (not at all like me) to 4 (very much like me). For positive urgency, a sample item is: "When I am very happy, I tend to do things that may cause problems in my life." For negative urgency, a sample item is: "When I am upset I often act without thinking." Because positive and negative urgency are facets of a single domain, we investigated (a) the correlation between the two in this sample and (b) whether use of one individual trait produced different results from use of the other individual trait. The two correlated highly: $r=.63, p<.001$ at wave 1, with higher correlations in subsequent waves. Each of the predictive models we report was also run with each of the two traits individually. In each case, results were the same across traits. Accordingly, we report all results using the overall trait of urgency. Internal consistency estimates of reliability were high: $a=.91$ at wave 1 and higher subsequent waves. Scores were calculated as average item scores, so the range was from 1 to 4 . 
This measure also provided reliable assessments of sensation seeking (wave $1 \mathrm{a}=.79$, with higher estimates subsequent waves), lack of planning (wave $1 \mathrm{a}=.77$, with higher estimates subsequent waves), and lack of planning (wave $1 \mathrm{a}=.65$, with higher estimates subsequent waves). Concerning validity of the trait assessment, there is good convergent validity in the form of assessment of each trait across methods and good discriminant validity evidence distinguishing each trait from the other traits within method of assessment (Cyders \& Smith, 2007).

Drinking Styles Questionnaire (DSQ: Smith, McCarthy \& Goldman, 1995) was used to measure self-reported drinker status when the children were in $5^{\text {th }}$ grade and drinking frequency when the children were in $7^{\text {th }}$ and $9^{\text {th }}$ grades. The DSQ measures drinking frequency with a single item asking how often one drinks alcohol. Frequency of drinking was measured at levels ranging from 1-4 times in one's life to almost daily. This assessment method has proven stable over time and there is good evidence for its validity (Settles et al., 2010).

Eating Disorder Examination- Questionnaire (EDE-Q; Fairburn \& Beglin, 1994). We used the EDE-Q, which is a self-report version of the Eating Disorders Examination semistructured interview (Cooper \& Fairburn, 1993) to assess binge eating behavior. The EDE-Q has been shown to have good reliability and validity, particularly in clinical samples (Cooper \& Fairburn, 1993, Mond, Hay, Rogers, Owen \& Beaumont, 2004). As is typical in studies of youth, we adapted the EDE-Q by using age-appropriate wording, defining concepts that could possibly be difficult to understand, and shortening the length of time referred to in the questions to the past two weeks, per past recommendations (Carter, Stewart \& Fairburn, 2001).

To measure binge eating, we adopted an approach common in eating disorder research, which is to count a behavior as a binge eating episode when two EDE-Q items are endorsed: one that assesses episodes of eating what most people would regard as an unusually large amount of food and one that assessed loss of control during these episodes. There were seven response options, ranging from 0 days to every day in the past two weeks.

Smoking Behavior was measured using a single item. Frequency of smoking ranged from 1-4 times in their lives to almost daily. Numerous single item measures of self-reported cigarette smoking have been used successfully in studies of adolescents (e.g., Chassin et al., 2000).

Center for Epidemiological Studies-Depression Scale (CES-D: Radloff, 1991) was used to measure individual differences in depressive symptomology, as has previously been used in this age group (Clarke, Debar, Lynch, Powell, Gale, et al., 2005). The scale has proven reliable (internal consistency estimates ranging from .85 to .90 ) and valid in numerous studies; it is frequently used with children, adolescents, and adults (Clarke et al., 2005). We used CES-D total scores as interval scale indicators of depressive symptomology ( $a=.85$, initial assessment in current sample, with estimates increasing in subsequent waves). Possible scores on the scale range from 20 to 80 . 
The Pubertal Development Scale (PDS; Petersen, Crockett, Richards, \& Boxer, 1988). This scale consists of five questions for boys ("do you have facial hair yet?") and five questions for girls ("have you begun to have your period?") Evidence for reliability and validity are strong (Coleman \& Coleman, 2002). We used the common dichotomous classification of the PDS (Culbert, Burt, McGue, Iacono, \& Klump, 2009) as pre- pubertal or pubertal, with mean scores above 2.5 indicative of pubertal onset.

\section{Procedure}

The current study used data drawn from a larger longitudinal investigation of youth. Data for this study were collected in the spring of $5^{\text {th }}$ grade (elementary school: Wave 1 ), the fall of $7^{\text {th }}$ grade (middle school: Wave 2), and the spring of $9^{\text {th }}$ grade (high school: Wave 3). As was approved by the university's IRB, the participating school systems, and the funding agency (NIAAA), a passive-consent procedure was used. Each family was sent a letter, through the U.S. Mail, introducing the study. Families were asked to return an enclosed, stamped letter or call a phone number if they did not want their child to participate. Out of $1,9885^{\text {th }}$ graders in the participating schools, 1,906 participated in the study (95.9\%). Reasons for non-participation included declination of consent from parents, declination of assent from children, and language or cognitive difficulties.

The questionnaires were administered in 23 public elementary schools at wave 1, in 15 middle schools at wave 2, and in 7 high schools at wave 3 . Questionnaires were administered by study staff in the children's classrooms or in a central location, such as the school cafeteria, during school hours. The questionnaires took 60 minutes or less to complete. Children who left the school system were asked to continue to participate. Those who consented did so either by completing hard copies of questionnaires delivered through the mail or by completing the measures on a secure web site.

Of the full sample, the percentages of individuals who participated at each wave were $96.5 \%$ at wave $1,90.1 \%$ at wave 2 (18 months following wave 1 ), and $75 \%$ at wave 3 (48 months following wave 1). Retained and not retained participants did not vary on any study variables. We have reported on all measures analyzed for this article. The sample size was determined at the start of the four-year longitudinal study to provide a powerful, representative sample of youth.

\section{Data Analysis}

Measurement of addictive behaviors-We measured three addictive behaviors: drinking, smoking, and binge eating. For each of the three, individuals endorsed a level of engagement that ranged from $0=$ "Never engaged in the behavior" to a maximum level reflecting engagement in the behavior "daily or almost daily." Specifically, for drinking, $0=$ "I have never had a drink of alcohol," 1 = "I have only had 1, 2, 3, or 4 drinks of alcohol in my life," 2 = "I only drink alcohol 3 or 4 times a year," 3 = "I drink alcohol about once a month," 4 = "I drink alcohol once or twice a week," and 5 = "I drink alcohol almost daily." For smoking: 0 = "I have never smoked," 1 = "I have smoked 1, 2, 3, or 4 times in my life," $2=$ "I smoke cigarettes 3 or 4 times a year," 3 = "I smoke about once a month," 4 = "I smoke about once or twice a week," and $5=$ "I smoke almost daily or every day." For binge 
eating, how many days in the last 14 days an individual engaged in binge eating with loss of control: 0 = "No days," 1 = "1-2 days," 2 = "3-4 days," 3 = "5-7 days," $4=$ = $8-10$ days," $5=$ "11-13 days," and $6=$ "14 days or every day."

For waves 2 and 3 of the current study, there was sufficient engagement in each addictive behavior to support scoring those variables as ordered categorical variables. For wave 1, when the participants were still in elementary school, the rate and frequency of the behaviors was so low that we modeled drinking, smoking and binge eating status each as dichotomous variables, reflecting the lifetime presence or absence of alcohol consumption, cigarette smoking, and binge eating. This decision was consistent with the evidence, cited above, indicating the association of simple engagement in these behaviors in children this young with dysfunction.

Model test-Structural equation modeling (SEM) was used to test the predictive model; the software we used was Mplus (Muthén \& Muthén, 2004-2010). We used the WSLMV estimation method, which accommodates ordered categorical variables. Each model allowed for cross-sectional correlations between all variables or disturbance terms.

The model we tested provided for: (1) cross-sectional associations between all variables within wave, (2) autoregressive prediction from each variable to the same variable the following wave, (3) reciprocal prediction between drinking and smoking, (4) prediction from wave 2 urgency to wave 3 drinking, smoking, binge eating, and depression, and (5) the key test of the study, which was prediction from wave 1 drinking, smoking, binge eating, and depression to wave 2 urgency. In addition, once we identified predictors of wave 2 urgency, we tested mediation hypotheses of the form that the predictive influence of the wave 1 predictors on wave 3 outcomes was mediated by wave 2 urgency.

To measure model fit, we relied on three fit indices: the Comparative Fix Index (CFI), the Nonnormed Fit Index (NNFI), and the root mean square error of approximation (RMSEA). Guidelines for what constitutes good fit vary. CFI and NNFI values above either .90 or 95 are thought to represent very good fit (Hu \& Bentler, 1999; Kline, 2005). RMSEA values of .06 or lower are thought to indicate a close fit, .08 a fair fit, and .10 a marginal fit (Browne \& Cudeck, 1993; Hu \& Bentler, 1999). Models are judged to fit the data well when good fit is supported by most fit indices. We also report the model chi-square.

\section{Results}

\section{Attrition and Treatment of Missing Data}

Of the full sample of 1,906 participants, 1843 participated at Wave 1 (96.7\%), 1721 participated at Wave $2(90.3 \%)$, and 1434 (75.2\%) participated at Wave 3. Those who participated at all waves did not differ from those who participated in fewer waves on any study variables. We therefore assumed data were missing at random and used the expectation maximization (EM) procedure to impute values for the missing data points. This procedure has been shown to produce relatively unbiased population parameter estimates and to be superior to traditional methods (Little \& Rubin, 1989). As a result, we were able to make full use of the entire sample of $n=1,906$. 


\section{Possible Effects due to School Membership}

In order to determine whether there was significant covariance among the study variables due to participants attending the same school, we calculated intraclass coefficients for each variable (using elementary school membership, $n=23$, as the nesting variable). Intraclass coefficients ranged from .03 to .00 . We therefore concluded that school membership was essentially unrelated to study variables.

\section{Descriptive Statistics}

Table 1 presents the percentage of youth positive for drinking, smoking, and binge eating at wave 1 and count frequencies of all three behaviors at waves 2 and 3. As noted in the table, engagement in drinking and smoking behavior increased steadily across the three waves. The percentage of youth engaging in binge eating changed little from wave 1 to wave 2, but increased at wave 3. Descriptive statistics for urgency scores and depression scores at all three waves remained fairly stable throughout the study timeframe, as expected: Wave 1: urgency mean $=2.17$ (standard deviation $(\mathrm{SD})=.63)$, depression mean $=34.70(\mathrm{SD}=8.43)$; Wave 2: urgency mean $=2.13(\mathrm{SD}=.66)$, depression mean $=34.13(\mathrm{SD}=9.88)$, Wave 3 : urgency mean $=2.18(\mathrm{SD}=.67)$, depression mean $=36.48(\mathrm{SD}=9.58)$. A correlation matrix of all study variables is provided in Table $\mathrm{S} 1$ of the on-line supplement.

\section{Model Tests}

The model fit the data well: $\chi^{2}(40)=262.85 ; p<.001 ; \mathrm{CFI}=.97$;NFI $=.91 ; \mathrm{RMSEA}=$. 05. Because this model included numerous predictive pathways, Figure 1 presents the model with arrows included for all statistically significant time-lagged pathways and Table 2 presents the path value estimates and confidence intervals for each of those significant predictive pathways. We next summarize the results in accordance with our main hypotheses.

Predictors of increases in urgency-Wave 1 drinker status (dichotomous) and Wave 1 depression predicted urgency scores at Wave 2 (18 months later); these variables predicted urgency in the positive direction and beyond the other predictors, including autoregressive prediction. The path coefficients provided in Table 2 are unstandardized weights, and thus provide one indication of the magnitude of the predictive effect. Being positive for drinker status at wave 1 predicted wave 2 urgency with beta $=.28$, indicating that being a drinker was associated with .28 raw units increase in urgency 18 months later above and beyond prediction from the other variables in the model. Because urgency scores were calculated as the mean of the urgency items and scores ranged from 1 to 4, a .28 units increase reflects a . 28 increase in the average item score, or an increase of .44 standard deviations in urgency over 18 months. A one unit increase in total depressive symptoms, where the range of scores was 60 units, was associated with a .01 increase in the average urgency item 18 months later (.02 standard deviations), beyond prediction from other variables.

High school criteria predicted by middle school urgency-Urgency measured at Wave 2 significantly predicted all the Wave 3 variables of interest (high school drinking, smoking, binge eating, and depression); higher levels of urgency in middle school predicted transdiagnostic risk in the form of higher levels of maladaptive behavioral engagement and 
depression in high school. As noted in Table 2, the magnitude of urgency's net prediction was moderate for the three addictive behaviors and small for depression.

Mediation tests (Table 3)-The results shown in Table 3 demonstrate that statistical analyses were consistent with the hypothesis that $5^{\text {th }}$ grade (Wave 1) drinking's prediction of each of the $9^{\text {th }}$ grade (Wave 3 ) criteria was mediated by $7^{\text {th }}$ grade (Wave 2) urgency levels. The results were also consistent with the hypothesis that $5^{\text {th }}$ grade depressive symptoms' prediction of each $9^{\text {th }}$ grade criterion was mediated by $7^{\text {th }}$ grade urgency. We only tested mediation from $5^{\text {th }}$ grade drinker status and depression because they were the only variables to predict increases in urgency in $7^{\text {th }}$ grade. As indicated in Table 3 , the magnitude of the mediation effects from drinker status through urgency was substantial, whereas those from depression through urgency were quite small.

Specificity of urgency-In order to test whether bottom-up, behavior based personality change was indeed particular to urgency, and not the other impulsivity-related traits of sensation seeking, lack of planning, and lack of perseverance, we ran the aforementioned model with each of these other traits. Increases in sensation seeking, lack of planning, and lack of perseverance in $7^{\text {th }}$ grade were not predicted from engagement in emotion-driven rash actions, such as drinking, or depressive symptoms in $5^{\text {th }}$ grade. Prediction of personality change was specific to the trait of urgency.

Additional pathways of note-As can be seen in Figure 1, there were several other significant predictions that were not emphasized in our hypothesis tests. First, all of the autoregressive pathways were significant. The autoregressions for urgency were particularly high, which indicates that, overall, there was a large degree of construct stability for urgency. Second, there was a reciprocal predictive relationship between drinking behavior and smoking behavior such that each predicted the other at each wave (Wave 1 drinker status predicted Wave 2 smoking, Wave 1 smoker status predicted Wave 2 drinking, Wave 2 drinking predicted Wave 3 smoking and Wave 2 smoking predicted Wave 3 drinking) above and beyond their autoregressive predictions. Finally, although Wave 1 binge eating status did not predict urgency change, Wave 1 urgency predicted Wave 2 binge eating above and beyond the binge eating autoregression, and these elevations in binge eating at Wave 2 predicted further elevations in urgency at Wave 3. The same pattern was true for the relationship between binge eating and depression, such that Wave 1 binge eating status did not predict depression at Wave 2, but Wave 1 depression predicted Wave 2 binge eating above and beyond the binge eating autoregression, and these elevations in binge eating at Wave 2 predicted further elevations in depression at Wave 3.

\section{Discussion}

The findings of this study are consistent with the possibility that there is adolescent personality change other than the change described by models of normal development (Littlefield, Stevens, Ellingson, King, \& Jackson, 2015). Middle school urgency levels can be predicted in advance by the behavior of elementary school children; this prediction is beyond that provided by prior urgency levels. Such change in high-risk personality variables appears to occur in a maladaptive direction, in the form of increases in the trait of urgency 
that are detectable in middle school. Urgency levels, in turn, predicted several dysfunctional behaviors by high school. Given past findings that urgency elevations also predict nonalcohol drug use, risky sexual behavior, non-suicidal self-injury, and gambling (Smith \& Cyders, 2016), the negative downstream consequences of urgency elevations are probably greater than represented in this study.

The finding that elementary school drinker status and depression symptom level predict increases in urgency, and thus multiple forms of subsequent psychological dysfunction, is important for psychological theory as well as for public health. Concerning theory, it is important to investigate possible mechanisms of personality change. With respect to prediction from drinker status, it is unlikely that substantive changes in personality are caused by the simple act of consuming an alcoholic beverage. It is much more likely that drinking behavior represents an important marker of a network of problem behaviors and emotional distress. This possibility is consistent with the numerous maladaptive behaviors associated with very early drinking (Guttmannova et al., 2012).

With respect to the modest prediction from elementary school depression symptoms, it may be that depressive symptom level is associated with a greater frequency of experiencing stress and distress, and that frequent experience of those affective states may increase the likelihood that one will act rashly for immediate emotional modulation. The finding of additive prediction of urgency from early drinking and depressive symptoms supports the conjecture that the experience of multiple problem behaviors and emotional distress may contribute to increases in urgency. Under this hypothesis, the current study measured markers of this broader process by measuring drinker status and depression.

Among adolescents, there appears to be personality change as part of normal development. Areas of the brain often referred to as part of the socioemotional system (the amygdala and ventral striatum, in particular) develop early in adolescence, whereas parts of the prefrontal cortex involved in planning and modulation of affect-driven action propensities are not fully mature until early adulthood (Casey \& Caudle, 2013). As a result, early adolescence tends to be characterized by a well-developed responsiveness to emotion and reward, but a nascent capacity to modulate that responsiveness (Harden \& Tucker-Drob, 2011). Over the course of adolescence, one sees a decline in many impulsivity-related traits as the prefrontal cortex matures (Harden \& Tucker-Drob, 2011; Steinberg et al., 2008). In the current study, we demonstrated that, contra this normative change, some youth appear to experience increases in affect-driven impulsive tendencies, which involves non-normative change that is predictable by very early drinking.

Urgency theory holds that when a youth engages in a rash behavior when emotional, the rash behavior provides either negative reinforcement (distraction from distress if the youth was distressed) or positive reinforcement (enhancement of a positive affective experience), and in that way, both the behavior and the trait are reinforced (Smith \& Cyders, 2016). Thus, the present findings could mark a process in which youth experience reinforcement from numerous rash behaviors, thereby leading to personality change. Although the current findings are consistent with this view, this study did not test whether the mechanism indicated by urgency theory is operating. We did not assess affective state in relation to 
youth drinking. Future research is necessary to test this and other hypotheses concerning possible mechanisms of personality change.

Concerning public health, the negative effects of early drinking appear to extend beyond future drinking behavior itself. Very early drinking is currently assessed by health care practitioners who are following AAP guidelines; this assessment appears to be important in more ways than previously thought. From a practical standpoint, the AAP-recommended assessment of very early drinking is valuable because it is simple, fast (two questions), and well-validated (Chung et al., 2012; AAP \& NIAAA; 2011). A positive drinking screen increases the likelihood that the child or adolescent is at risk for increases in a maladaptive personality trait that can lead to far-reaching and long-lasting downstream health and behavior consequences.

As hypothesized, the finding that increases in maladaptive personality could be predicted from very early drinking behavior and depressive symptoms was specific to the trait of urgency. We found no evidence that drinking or depressive symptoms predicted change in sensation seeking, lack of planning, or lack of perseverance, all of which are impulsivityrelated traits that do not reflect affect-driven impulsive action. Interestingly, when modeling normative personality change in adolescents, change in urgency and sensation seeking are highly correlated (Littlefield et al., 2015). The current findings suggest that disruptions in that normative developmental process, as reflected by very early engagement in drinking or very early experience of depressive symptoms, may specifically influence the trait of urgency.

There were two other noteworthy findings from this study, namely, the reciprocal prediction between drinking and smoking behavior, and the reciprocal relationship between binge eating and depression. Although these were not the focal analyses of the study, the results demonstrate interesting patterns and would likely be fruitful areas for future research.

As is true in any longitudinal study, there was attrition over the four-year period. Although retained and non-retained participants did not differ on any study variables, we cannot rule out the possibility that the two groups differed on variables not measured in the current study, such as parental socioeconomic status, and that our results might have differed had there been no attrition. All variables were measured by questionnaire, so we did not have the opportunity to discuss the items with participants and answer their questions. Thus, even though there is good evidence for the validity of each measure used, we cannot know with certainty the impact of our assessment method on the results. Although our model test was driven by a priori theory, it is important to recognize that good fit of an SEM model does not preclude the possibility that alternative models may have fit the data equally well (Tomarken \& Waller, 2003), and readers should be aware of recent efforts to improve the ability to control for trait stability over time beyond autoregression controls (Hamaker, Kuiper, \& Grasman, 2015). Because our design was not experimental, the finding that drinking predicted personality does not provide confirmation of a causal process. Because $12 \%$ of the youth were positive for drinker status at the start of the study, we cannot know whether urgency levels prior to $5^{\text {th }}$ grade predicted $5^{\text {th }}$ grade drinking. It is certainly quite possible that there is a reciprocal influence process between drinking behavior and personality. In 
fact, the findings presented in Figure 1 are consistent with that possibility, which merits further exploration.

Strikingly, $5^{\text {th }}$ grade drinker status and depressive symptom level predicted increases in a high-risk personality trait that disposes individuals to act impulsively in response to strong emotion, and this trait, in turn, predicted numerous negative outcomes in high school. It thus seems possible that personality can change in a maladaptive direction during adolescence in a way that alters life trajectories in negative ways.

\section{Supplementary Material}

Refer to Web version on PubMed Central for supplementary material.

\section{Acknowledgments}

The authors gratefully acknowledge research support from the National Institute on Alcohol Abuse and Alcoholism as well as the National Institute on Drug Abuse with the National Institutes of Health under award numbers R01 AA016166 to Gregory Smith and T32DA035200 Craig Rush. The content is solely the responsibility of the authors and does not necessarily represent the official views of the National Institutes of Health.

\section{References}

American Academy of Pediatrics \& National Institute on Alcohol Abuse and Alcoholism. Alcohol Screening and Brief Intervention for Youth: A Practitioner's Guide. NIH Publication. 2011; 11-7805:1-41.

Baker TB, Brandon TH, Chassin L. Motivational influences on cigarette smoking. Annual Review of Psychology. 2004; 55:463-491.

Berg, JM., Latzman, RD., Bliwise, NG., Lilienfeld, SO. Parsing the Heterogeneity of Impulsivity: A Meta-Analytic Review of the Behavioral Implications of the UPPS for Psychopathology. Online pre-publication. 2015. http://dx.doi.org/10.1037/pas0000111

Birkley EL, Smith GT. Recent advances in understanding the personality underpinnings of impulsive behavior and their role in risk for addictive behaviors. Current Drug Abuse Reviews. 2011; 4(4): 215-227. [PubMed: 22126707]

Bleidorn W. Hitting the Road to Adulthood Short-Term Personality Development During a Major Life Transition. Personality and Social Psychology Bulletin. 2012; 38(12):1594-1608. [PubMed: 22894876]

Blonigen DM, Durbin CE, Hicks BM, Johnson W, McGue M, Iacono WG. Alcohol use initiation is associated with changes in personality trait trajectories from early adolescence to young adulthood. Alcoholism: Clinical and Experimental Research. 2015; 39(11):2163-2170.

Browne MW, Cudeck R. Alternative ways of assessing model fit. Sage focus editions. 1993; 154:136136.

Carter JC, Stewart DA, Fairburn CG. Eating disorder examination questionnaire: Norms for young adolescent girls. Behavior Research and Therapy. 2001; 39(5):625-632.

Casey BJ, Caudle K. The teenage brain: Self control. Current Directions in Psychological Science. 2013; 22:82-87. [PubMed: 25284961]

Caspi A, Harrington H, Milne B, Amell JW, Theodore RF, Moffitt TE. Children's behavioral styles at age 3 are linked to their adult personality traits at age 26. Journal of Personality. 2003; 71(4):495514. [PubMed: 12901429]

Chassin L, Presson CC, Pitts SC, Sherman SJ. The natural history of cigarette smoking from adolescence to adulthood in a midwestern community sample: multiple trajectories and their psychosocial correlates. Health Psychology. 2000; 19(3):223-231. [PubMed: 10868766] 
Chung T, Smith GT, Donovan JE, Windle M, Faden VB, Chen CM, Martin CS. Drinking frequency as a brief screen for adolescent alcohol problems. Pediatrics. 2012; 129(2):205-212. [PubMed: 22218839]

Clarke G, Debar L, Lynch F, Powell J, Gale J, O'Connor E, et al. Hertert S. A randomized effectiveness trial of brief cognitive-behavioral therapy for depressed adolescents receiving antidepressant medication. Journal of the American Academy of Child \& Adolescent Psychiatry. 2005; 44(9): 888-898. [PubMed: 16113617]

Coleman L, Coleman J. The measurement of puberty: a review. Journal of Adolescence. 2002; 25(5): 535-550. [PubMed: 12234559]

Combs JL, Pearson CM, Smith GT. A risk model for preadolescent disordered eating. International Journal of Eating Disorders. 2011; 44(7):596-604. [PubMed: 21997422]

Combs JL, Pearson CM, Zapolski TC, Smith GT. Preadolescent disordered eating predicts subsequent eating dysfunction. Journal of Pediatric Psychology. 2012; :1-9. DOI: 10.1093/jpepsy/jss094

Combs JL, Spillane NS, Caudill L, Stark B, Smith GT. The acquired preparedness risk model applied to smoking in 5th grade children. Addictive Behaviors. 2012; 37(3):331-334. [PubMed: 22143003]

Cooper MJ, Fairburn CG. Demographic and clinical correlates of selective information-processing in patients with bulimia- nervosa. International Journal of Eating Disorders. 1993; 13(1):109-116. [PubMed: 8477270]

Coskunpinar A, Dir AL, Cyders MA. Multidimensionality in impulsivity and alcohol Use: a metaanalysis using the UPPS model of impulsivity. Alcoholism: Clinical and Experimental Research. 2013; 37(9):1441-1450.

Costa PT, Herbst JH, McCrae RR, Siegler IC. Personality at midlife: Stability, intrinsic maturation, and response to life events. Assessment. 2000; 7(4):365-378. [PubMed: 11151962]

Costa, PT., Jr, McCrae, RR. Mood and personality in adulthood. In: Magia, C., McFadden, SH., editors. Handbook of Emotion, Adult Development, and Aging. Academic Press; San Diego: 1996.

Culbert KM, Burt SA, McGue M, Iacono WG, Klump KL. Puberty and the genetic diathesis of disordered eating attitudes and behaviors. Journal of Abnormal Psychology. 2009; 118(4):788796. [PubMed: 19899848]

Cyders MA, Flory K, Rainer S, Smith GT. The role of personality dispositions to risky behavior in predicting first-year college drinking. Addiction. 2009; 104(2):193-202. [PubMed: 19149813]

Cyders MA, Smith GT. Mood-based rash action and its components: Positive and negative urgency. Personality and Individual Differences. 2007; 43(4):839-850.

Cyders MA, Smith GT. Emotion-based dispositions to rash action: positive and negative urgency. Psychological Bulletin. 2008a; 134(6):807-828. [PubMed: 18954158]

Cyders MA, Smith GT. Clarifying the role of personality dispositions in risk for increased gambling behavior. Personality and Individual Differences. 2008b; 45(6):503-508. [PubMed: 19088857]

Donovan JE. Really underage drinkers: The epidemiology of children's alcohol use in the United States. Prevention Science. 2007; 8(3):192-205. [PubMed: 17629790]

Doran N, Khoddam R, Sanders PE, Schweizer CA, Trim RS, Myers MG. A prospective study of the acquired preparedness model: The effects of impulsivity and expectancies on smoking initiation in college students. Psychology of Addictive Behaviors. 2013; 27(3):714-722. [PubMed: 22686965]

Fairburn CG, Beglin SJ. Assessment of eating disorders: Interview or self-report questionnaire? International Journal of Eating Disorders. 1994; 16(4):363-370. [PubMed: 7866415]

Fischer S, Smith GT, Cyders MA. Another look at impulsivity: A meta-analytic review comparing specific dispositions to rash action in their relationship to bulimic symptoms. Clinical Psychology Review. 2008; 28(8):1413-1425. [PubMed: 18848741]

Fischer S, Peterson CM, McCarthy D. A prospective test of the influence of negative urgency and expectancies on binge eating and purging. Psychology of Addictive Behaviors. 2013; 27(1):294300. [PubMed: 22823545]

Guttmannova K, Hill KG, Bailey JA, Lee JO, Hartigan LA, Hawkins JD, Catalano RF. Examining explanatory mechanisms of the effects of early alcohol use on young adult alcohol dependence. Journal of Studies on Alcohol and Drugs. 2012; 73(3):379-390. [PubMed: 22456243] 
Haedt-Matt AA, Keel PK. Revisiting the affect regulation model of binge eating: A meta-analysis of studies using ecological momentary assessment. Psychological Bulletin. 2011; 137(4):660-681. [PubMed: 21574678]

Hamaker EL, Kuiper RM, Grasman RPPP. A critique of the cross-lagged panel model. Psychological Methods. 2015; 20:102-116. [PubMed: 25822208]

Harden KP, Tucker-Drob EM. Individual differences in the development of sensation seeking and impulsivity during adolescence: Further evidence for a dual systems model. Developmental Psychology. 2011; 47(3):739-746. [PubMed: 21534657]

Horvath LS, Milich R, Lynam D, Leukefeld C, Clayton R. Sensation Seeking and Substance Use: A Cross-Lagged Panel Design. Individual Differences Research. 2004; 2(3):175-183.

$\mathrm{Hu}$ LT, Bentler PM. Cutoff criteria for fit indexes in covariance structure analysis: Conventional criteria versus new alternatives. Structural Equation Modeling: a Multidisciplinary Journal. 1999; $6(1): 1-55$.

Jang KL, Livesley WJ, Vernon PA. The genetic basis of personality at different ages: a cross-sectional twin study. Personality and Individual Differences. 1996; 21(2):299-301.

Kline, RB. Principles and Practice of Structural Equation Modeling. New York: Guilford Press; 2005.

Kotler LA, Cohen P, Davies M, Pine DS, Walsh BT. Longitudinal relationships between childhood, adolescent, and adult eating disorders. Journal of the American Academy of Child \& Adolescent Psychiatry. 2001; 40(12):1434-1440. [PubMed: 11765289]

Little RJ, Rubin DB. The analysis of social science data with missing values. Sociological Methods \& Research. 1989; 18(2-3):292-326.

Littlefield AK, Stevens AK, Ellingson JM, King KM, Jackson KM. Changes in negative urgency, positive urgency, and sensation seeking across adolescence. Personality and Individual Differences. 2015; 90:332-337.

Littlefield AK, Vergés A, Wood PK, Sher KJ. Transactional models between personality and alcohol involvement: A further examination. Journal of Abnormal Psychology. 2012; 121(3):778-783. [PubMed: 22288908]

McCrae RR, Costa PT. The stability of personality: Observations and evaluations. Current Directions in Psychological Science. 1994; 3(6):173-175.

Mond JM, Hay PJ, Rodgers B, Owen C, Beumont PJV. Temporal stability of the eating disorder examination questionnaire. International Journal of Eating Disorders. 2004; 36(2):195-203. [PubMed: 15282689]

Muthén, LK., Muthén, BO. Mplus: The comprehensive modeling program for applied researchers User's guide. 3rd. Los Angeles, CA: Muthen \& Muthen; 2004-2010.

Pearson CM, Combs JL, Zapolski TC, Smith GT. A longitudinal transactional risk model for early eating disorder onset. Journal of Abnormal Psychology. 2012; 121(3):707-718. [PubMed: 22428790]

Petersen AC, Crockett L, Richards M, Boxer A. A self-report measure of pubertal status: Reliability, validity, and initial norms. Journal of Youth and Adolescence. 1988; 17(2):117-133. [PubMed: 24277579]

Radloff LS. The use of the Center for Epidemiologic Studies Depression Scale in adolescents and young adults. Journal of Youth and Adolescence. 1991; 20(2):149-166. [PubMed: 24265004]

Riley EN, Combs JL, Jordan CE, Smith GT. Negative Urgency and Lack of Perseverance: Identification of Differential Pathways of Onset and Maintenance Risk in the Longitudinal Prediction of Nonsuicidal Self-Injury. Behavior Therapy. 2015; 46:439-448. [PubMed: 26163709]

Roberts BW, Caspi A, Moffitt TE. Work experiences and personality development in young adulthood. Journal of Personality and Social Psychology. 2003; 84(3):582-593. [PubMed: 12635918]

Roberts BW, DelVecchio WF. The rank-order consistency of personality traits from childhood to old age: a quantitative review of longitudinal studies. Psychological Bulletin. 2000; 126(1):3-25. [PubMed: 10668348]

Roberts BW, Kuncel NR, Shiner R, Caspi A, Goldberg LR. The power of personality: The comparative validity of personality traits, socioeconomic status, and cognitive ability for predicting important life outcomes. Perspectives on Psychological Science. 2007; 2(4):313-345. [PubMed: 26151971] 
Roberts BW, Walton K, Bogg T, Caspi A. De-investment in work and non-normative personality trait change in young adulthood. European Journal of Personality. 2006; 20(6):461-474.

Roberts BW, Wood D, Caspi A. The development of personality traits in adulthood. Handbook of Personality: Theory and Research. 2008; 3:375-398.

Settles RF, Cyders M, Smith GT. Longitudinal validation of the acquired preparedness model of drinking risk. Psychology of Addictive Behaviors. 2010; 24(2):198-208. [PubMed: 20565146]

Settles RE, Zapolski TC, Smith GT. Longitudinal test of a developmental model of the transition to early drinking. Journal of Abnormal Psychology. 2014; 123(1):141-151. [PubMed: 24661166]

Sher KJ, Trull TJ. Personality and disinhibitory psychopathology: alcoholism and antisocial personality disorder. Journal of Abnormal Psychology. 1994; 103(1):92-102. [PubMed: 8040486]

Shiner RL, Masten AS. Transactional links between personality and adaptation from childhood through adulthood. Journal of Research in Personality. 2002; 36(6):580-588.

Smith GT, Cyders MA. Integrating affect and impulsivity: The role of positive and negative urgency in substance use risk. Drug and Alcohol Dependence. 2016; 163:S3-S12. [PubMed: 27306729]

Smith, GT., Guller, L. Psychological underpinnings to impulsive behavior. In: Cooper, ML., Larsen, R., editors. APA Handbook of Personality and Social Psychology. Vol. IV. Washington, D C.: American Psychological Association; 2014. p. 329-350.

Smith GT, Guller L, Zapolski TC. A Comparison of Two Models of Urgency: Urgency Predicts Both Rash Action and Depression in Youth. Clinical Psychological Science. 2013; 1:266-275. [PubMed: 25419495]

Smith GT, McCarthy DM, Goldman MS. Self-reported drinking and alcohol-related problems among early adolescents: Dimensionality and validity over 24 months. Journal of Studies on Alcohol and Drugs. 1995; 56(4):383-394.

Smyth JM, Wonderlich SA, Heron KE, Sliwinski MJ, Crosby RD, Mitchell JE, Engel SG. Daily and momentary mood and stress are associated with binge eating and vomiting in bulimia nervosa patients in the natural environment. Journal of Consulting and Clinical Psychology. 2007; 75(4): 629-638. [PubMed: 17663616]

Somerville LH, Jones RM, Casey BJ. A time of change: behavioral and neural correlates of adolescent sensitivity to appetitive and aversive environmental cues. Brain and Cognition. 2010; 72(1):124133. [PubMed: 19695759]

Stautz K, Cooper A. Impulsivity-related personality traits and adolescent alcohol use: a meta-analytic review. Clinical Psychology Review. 2013; 33(4):574-592. [PubMed: 23563081]

Steinberg L, Albert D, Cauffman E, Banich M, Graham S, Woolard J. Age differences in sensation seeking and impulsivity as indexed by behavior and self-report: evidence for a dual systems model. Developmental Psychology. 2008; 44(6):1764-1778. [PubMed: 18999337]

Stice E, Martinez EE. Cigarette smoking prospectively predicts retarded physical growth among female adolescents. Journal of Adolescent Health. 2005; 37(5):363-370. [PubMed: 16227120]

Swendson JD, Tennen H, Carney MA, Affleck G, Willard A, Hromi A. Mood and alcohol consumption: An experience sampling test of the self-medication hypothesis. Journal of Abnormal Psychology. 2000; 109:198-204. [PubMed: 10895557]

Tanofsky-Kraff M, Shomaker LB, Olsen C, Roza CA, Wolkoff LE, Columbo KM, et al. Yanovski JA. A prospective study of pediatric loss of control eating and psychological outcomes. Journal of Abnormal Psychology. 2011; 120(1):108-118. [PubMed: 21114355]

Tarter, R. The high-risk paradigm in alcohol and drug abuse research. In: Pickens, R., Svikis, D., editors. Biological Vulnerability to Drug Abuse (Vol NIDA Research Monograph. Vol. 89. Rockville, MD: National Institute on Drug Abuse; 1988. p. 73-86.

Tomarken AJ, Waller NG. Potential problems with "well fitting” models. Journal of Abnormal Psychology. 2003; 112:578-598. [PubMed: 14674870]

Whiteside SP, Lynam DR. The five factor model and impulsivity: Using a structural model of personality to understand impulsivity. Personality and Individual Differences. 2001; 30(4):669689.

Widiger, TA., Smith, GT. Personality and psychopathology. In: John, O.Robins, RW., Pervin, L., editors. Handbook of Personality: Theory and Research. Third. NY: Guilford; 2008. p. 743-769. 
Zapolski TC, Cyders MA, Smith GT. Positive urgency predicts illegal drug use and risky sexual behavior. Psychology of Addictive Behaviors. 2009; 23(2):348-354. [PubMed: 19586152]

Zapolski TC, Stairs AM, Settles RF, Combs JL, Smith GT. The measurement of dispositions to rash action in children. Assessment. 2010; 17(1):116-125. [PubMed: 19955108]

Zuckerman, M. Behavioral expressions and biosocial bases of sensation seeking. Cambridge University Press; 1994. 


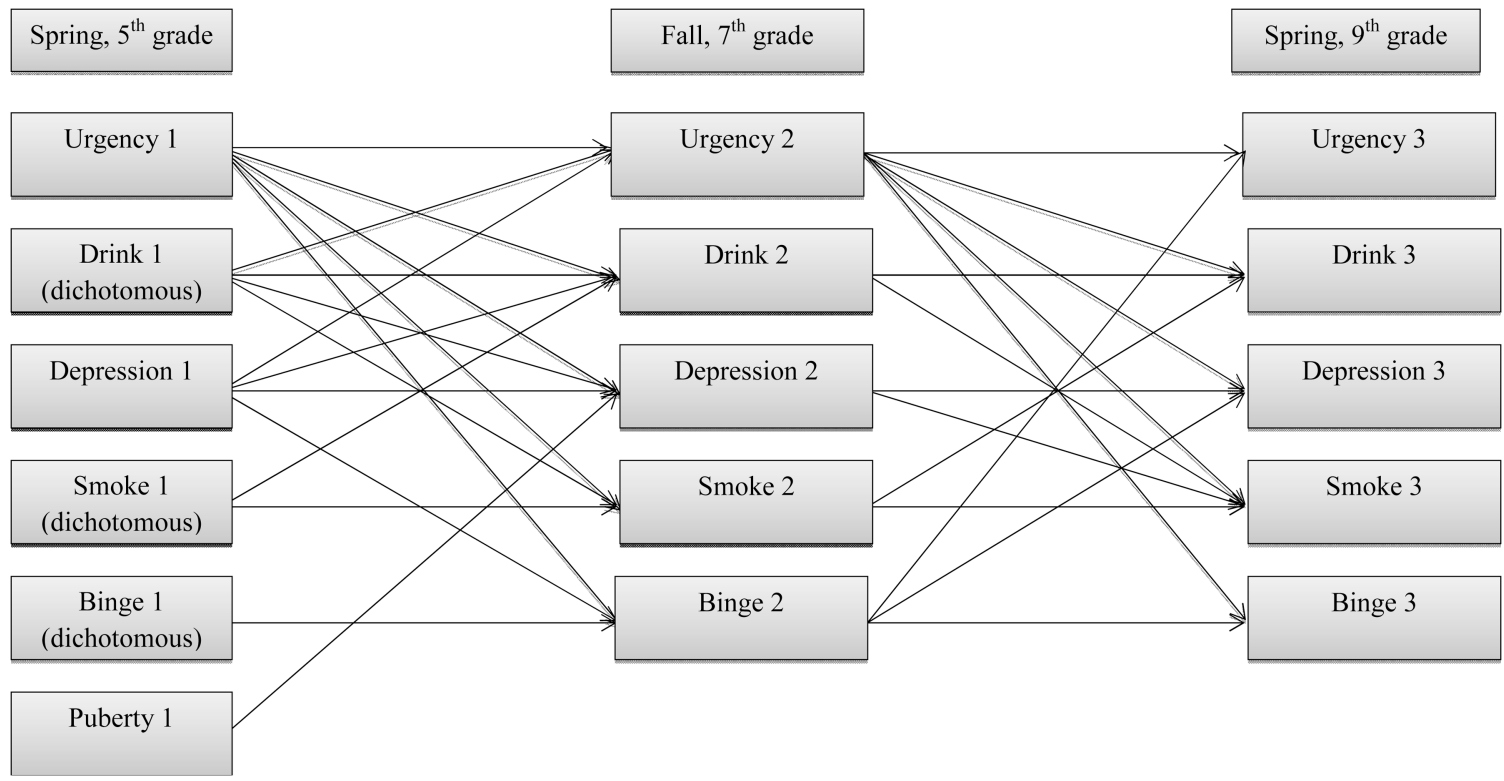

Figure 1. Broad risk implications of early drinker status through urgency change Note. $\mathrm{N}=1,906$. Spring, $5^{\text {th }}$ grade: elementary school. Fall, $7^{\text {th }}$ grade: middle school. Spring, $9^{\text {th }}$ grade: high school. All solid line pathways were significantly greater than zero. Drink $1=$ drinker status assessed at Time 1 . Drink 2 and Drink $3=$ drinking behavior at Time 2 and Time 3, measured as an ordinal variable. Smoke $1=$ smoker status at Time 1 . Smoke 2 and Smoke 3 = smoking behavior at Time 2 and Time 3, ordinal variable. Binge 1 $=$ binge eater status at Time 1 . Binge 2 and Binge $3=$ binge eating behavior at Time 2 and Time 3, ordinal variable. Path estimates are provided in Table 2. 


\section{름}

ฮั

क्ष

के

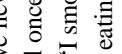

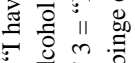

II ब

sio

雪

하

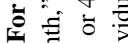

के

.

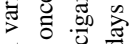

ड

表完

응

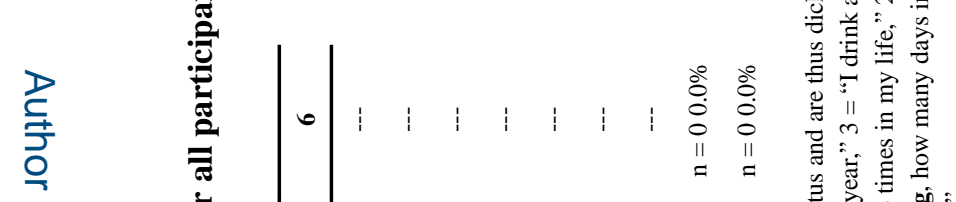

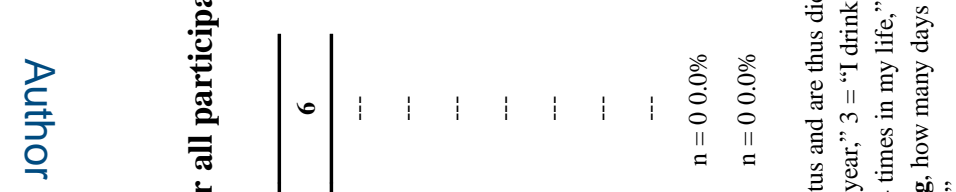

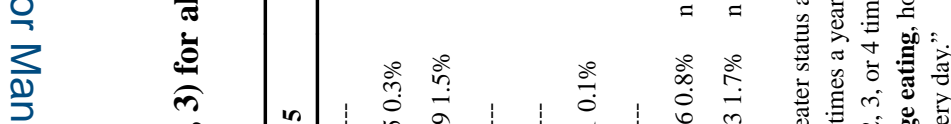

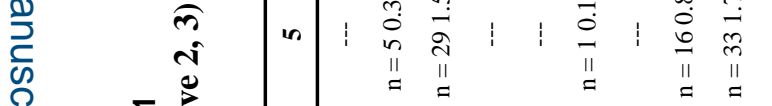

言.

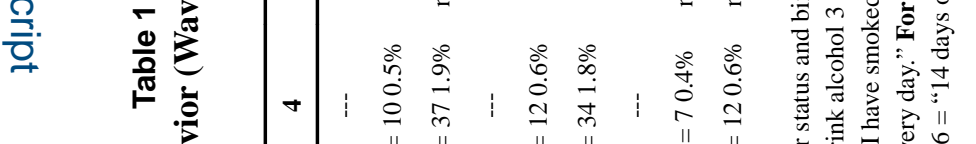

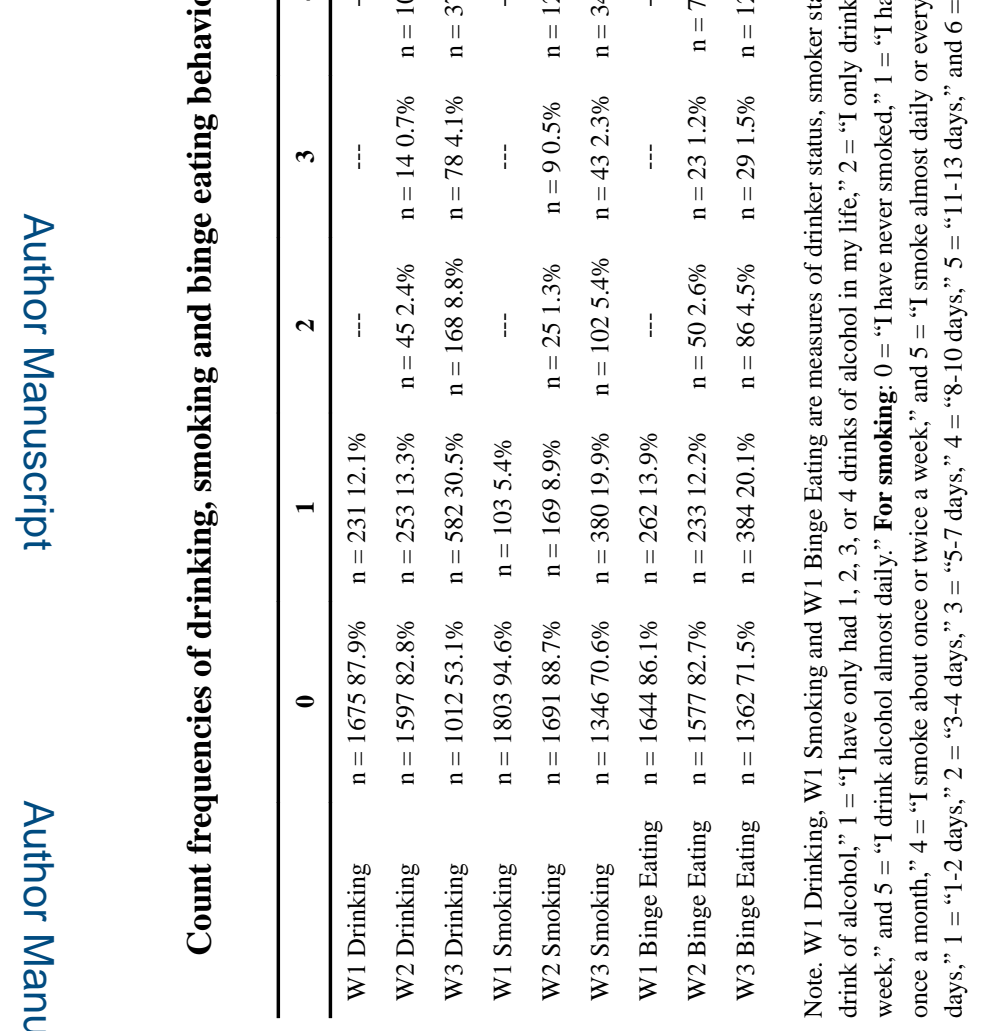

Clin Psychol Sci. Author manuscript; available in PMC 2018 January 01. 


\section{Table 2}

Path value estimates for Figure 1

\begin{tabular}{|c|c|c|}
\hline Pathway & Path Estimate & 95\% Confidence Interval \\
\hline \multicolumn{3}{|l|}{ Predictors of Wave 2 Urgency } \\
\hline Wave 1 Urgency & $.45^{* *}$ & $.40-.49$ \\
\hline Wave 1 Drinker Status & $.28^{* *}$ & $.10-.46$ \\
\hline Wave 1 Depression & $.01^{* *}$ & $.01-.02$ \\
\hline \multicolumn{3}{|c|}{ Predictors of Wave 2 Drinking } \\
\hline Wave 1 Drinker Status & $2.29^{* *}$ & $1.97-2.60$ \\
\hline Wave 1 Urgency & $.11^{*}$ & $.00-.22$ \\
\hline Wave 1 Smoker Status & $.63^{* *}$ & $.20-1.06$ \\
\hline Wave 1 Depression & $.02^{* *}$ & $.01-.03$ \\
\hline \multicolumn{3}{|c|}{ Predictors of Wave 2 Smoking } \\
\hline Wave 1 Smoker Status & $1.79^{* * *}$ & $1.35-2.23$ \\
\hline Wave 1 Urgency & $.23^{* *}$ & $.10-.36$ \\
\hline Wave 1 Drinker Status & $1.20^{* *}$ & $.83-1.56$ \\
\hline \multicolumn{3}{|c|}{ Predictors of Wave 2 Binge Eating } \\
\hline Wave 1 Binge Eater Status & $1.04^{* *}$ & $.78-1.30$ \\
\hline Wave 1 Urgency & $.19^{* *}$ & $.08-.29$ \\
\hline \multicolumn{3}{|c|}{ Predictors of Wave 2 Depression } \\
\hline Wave 1 Depression & $.37^{* *}$ & $.31-.43$ \\
\hline Wave 1 Urgency & $.72^{* *}$ & $.36-1.09$ \\
\hline Wave 1 Pubertal Status & $1.48^{* *}$ & $.42-2.54$ \\
\hline \multicolumn{3}{|c|}{ Predictors of Wave 3 Urgency } \\
\hline Wave 2 Urgency & $.39^{* *}$ & $.35-.44$ \\
\hline Wave 2 Binge Eating & $.09^{* *}$ & $.02-.17$ \\
\hline \multicolumn{3}{|c|}{ Predictors of Wave 3 Drinking } \\
\hline Wave 2 Drinking & $.86^{* *}$ & $.65-1.07$ \\
\hline Wave 2 Urgency & $.27^{* *}$ & $.19-.35$ \\
\hline Wave 2 Smoking & $.31^{* *}$ & $.11-.51$ \\
\hline \multicolumn{3}{|c|}{ Predictors of Wave 3 Smoking } \\
\hline Wave 2 Smoking & $.82^{* *}$ & $.55-1.08$ \\
\hline Wave 2 Urgency & $.30^{* *}$ & $.21-.38$ \\
\hline Wave 2 Drinking & $.33^{* *}$ & $.13-.53$ \\
\hline Wave 2 Depression & $.02^{* *}$ & $.01-.03$ \\
\hline \multicolumn{3}{|c|}{ Predictors of Wave 3 Binge Eating } \\
\hline Wave 2 Binge Eating & $.65^{* *}$ & $.52-.77$ \\
\hline Wave 2 Urgency & $.16^{* *}$ & $.07-.24$ \\
\hline
\end{tabular}




\begin{tabular}{lcc}
\hline Pathway & Path Estimate & $\mathbf{9 5 \%}$ Confidence Interval \\
\hline \multicolumn{2}{c}{ Predictors of Wave 3 Depression } & \\
Wave 2 Depression & $.30^{* *}$ & $.24-.35$ \\
Wave 2 Urgency & $.84^{* *}$ & $.46-1.21$ \\
Wave 2 Binge Eating & $1.15^{* *}$ & $.47-1.83$ \\
Note: $n=1,906$. & \\
$*$ & \\
$\mathrm{p}<.05 ;$ & \\
$* *$ & \\
$\mathrm{p}<.001$. & \\
Values are unstandardized path coefficients.
\end{tabular}


Table 3

Test of mediation from elementary school drinking through middle school urgency to high school maladaptive behavior

\begin{tabular}{lccc}
\hline & Z Score & Beta & Confidence Interval \\
\hline $\mathrm{D} 1 \rightarrow \mathrm{U} 2 \rightarrow \mathrm{D} 3$ & $3.56^{* *}$ & 0.49 & $0.22-0.77$ \\
$\mathrm{Dep} 1 \rightarrow \mathrm{U} 2 \rightarrow \mathrm{D} 3$ & $2.23^{*}$ & 0.002 & $0.000-0.003^{a}$ \\
$\mathrm{D} 1 \rightarrow \mathrm{U} 2 \rightarrow \mathrm{B} 3$ & $3.72^{* *}$ & 0.29 & $0.02-0.55$ \\
$\mathrm{Dep} 1 \rightarrow \mathrm{U} 2 \rightarrow \mathrm{B} 3$ & $1.74^{*}$ & 0.001 & $0.000-0.002^{a}$ \\
$\mathrm{D} 1 \rightarrow \mathrm{U} 2 \rightarrow \mathrm{S} 3$ & $2.14^{*}$ & 0.52 & $0.25-0.79$ \\
$\mathrm{Dep} 1 \rightarrow \mathrm{U} 2 \rightarrow \mathrm{S} 3$ & $2.26^{*}$ & 0.002 & $0.000-0.003^{a}$ \\
$\mathrm{D} 1 \rightarrow \mathrm{U} 2 \rightarrow \mathrm{Dep} 3$ & $3.78^{* *}$ & 3.13 & $1.49-4.77$
\end{tabular}

Note. $N=1,906$. D1 = drinker status at Wave 1 (dichotomous). U2 = urgency scores measured at Wave 2. D3 = drinking scores measured at Wave 3 (ordinal variable) at Wave 3, Dep1 = depression scores measured at Wave 1; B3 = binge eating scores measured at Wave 3 (ordinal variable), S3 = smoking scores measured at Wave 3 (ordinal variable), Dep3 = depression scores measured at Wave 3 . We tested the significance of the mediation using a one-tailed test because the direction of the prediction was hypothesized in advance. Reported here are the unstandardized effects. The standardized indirect effects ranged from a low of $b=.08$ for the prediction of wave 3 binge eating to a high of $b=.12$ for the prediction of wave 3 drinking and wave 3 smoking.

* $=\mathrm{p}<.05$

$* * * 0<.01$

${ }^{a}$ The reason .00 is in these confidence intervals but the effects are noted as significantly greater than zero is that these paths were significantly greater than zero using our one-tailed tests but were not so using a two-tailed test. 